\title{
The Role of Law Enforcement in Community-Based Drug Treatment and its Impact on Crime Prevention
}

\author{
Krisanaphong Poothakool
}

\author{
Rangsit University and Royal Police Cadet Academy, Thailand
}

\begin{abstract}
In line with trends in other countries the Royal Thai Police acknowledges the need for more communityoriented approaches which are responsive to local contexts. However, the development of such approaches to policing needs also to engage with responses to illicit drug use locally, which would include a wider definition of harm reduction and accommodate the work of public health partners their initiatives, such as needle-exchange.

The present study examines the role of law enforcement officers in community-based drug treatment in the Chiang Mai region of the Upper North, through use of in-depth, qualitative interviews with key stakeholders, which included senior police, judges, public health managers, NGO workers and local community leaders.

Most interviewees expressed concern that not enough was being done to address drug use in local communities, and barriers to police adopting a harm reduction approach locally included government-directed arrest quotas and lack of experience in working co-operatively with public health partners. Effective police involvement required coordinated policy-change and officer training to develop understanding and ways of working to support community-based drug treatment.
\end{abstract}

Keywords: Policing, community-based drug treatment, harm reduction, Thailand.

\section{INTRODUCTION}

In Thailand, law enforcement functions are carried out by the Royal Thai Police (RTP) whose head, the Commissioner General, would usually report directly to the Prime Minister's Office, although at the time of writing the military were at the helm of state affairs due to political instability. As in other countries, the police role is to prevent and suppress crime and manage public order and safety. And as elsewhere, approaches to policing which recognize and are in accordance with local needs are vital to the prevention, detection, investigation and solution of crime-related matters. Effective policing is characterized by recognition of the need to work closely with local communities to not only prevent crimes and maintain public order, but also to secure legitimacy and promote transparency. Effective approaches to policing, therefore, require public consensus and support (Bayley, 2002).

As elsewhere, policing in Thailand often includes interactions with people affected by drug use and dependence. The police have to respond to the harms to local communities resulting from drug use such as property crimes theft, public disputes, family violence and quarrels, thus, policing is inextricably linked to drug-related issues. Whilst the police role in responding to drug-related crimes and public order concerns is well recognized, their role in proactively supporting -

*Address correspondence to this author at the Rangsit University and Royal Police Cadet Academy, Thailand; E-mail: k.poothakool@rsu.ac.th drug-related harm reduction often remains underrecognized, where enforcement of illicit drug laws forms part of populist government policies. Here, drugrelated harm reduction refers to reducing the adverse health, social and economic harms associated with illicit drug use without necessarily reducing drug consumption (Harm Reduction International, 2015). Particularly, police can contribute to the effectiveness of a community-based harm reduction approaches by considering options other than arrest or direct referral to residential (detention) centers for drug users, and assist the drug users in receiving assistance in the community (LEAHN, 2014). The United Nations Office on Drugs and Crime (UNODC) defines communitybased drug treatment as:

'A specific integrated model of treatment for people affected by drug use and dependence in the community which provides a continuum of care from outreach and low threshold services, through detoxification and stabilization to aftercare and integration, including maintenance pharmacotherapy'.

[UNODC, 2014]

Some global research suggests that hospitals and specialist alcohol and other drug clinical services are the most expensive way to provide services to People Who Use Drugs (PWUD) when compared to self-care and community care; and other research demonstrates that care and treatment delivered at the community 
level are in fact the most effective methods and cheapest services which can and should be provided (UNODC, 2008).

In Thailand, in a community-based treatment model, the aim would be for local institutions and communitybased organizations to formulate their own strategies in parallel to national drug policy, so as to address the specific needs of the local community, importantly, enabling different strategies to be created and implemented based on local context and resources (Poothakool, 2017). Reinforcing collaboration, training and advocacy between key stakeholders is necessary for effective community-based drug treatment and should include municipal governments, educational institutions, civil society organizations, non-government organizations (NGOs), business sectors, local people and police. Community-based treatment programs, supported by these stakeholders can have significant impacts on drug treatment and crime prevention outcomes in terms of preventive programs and the promotion of healthy lifestyles.

Community-based drug treatment is a sustainable alternative to compulsory treatment centers and would be a radical approach in Thailand $^{\dagger}$. It provides drug users with voluntary, cost-effective and rights-based drug treatment and care services in their local communities. Evidence has shown that patients using community-based services have a significant decrease in the number of hospital stays, emergency-room visits and criminality (UNODC, 2014). In addition, community-based drug treatment can reduce stigma and discrimination towards drug users and their families by raising awareness of and involvement among the community in responses to drug use (ONCB, 2018).

Given the stated benefits of community-based drug treatment programs, it follows that law enforcement officers in Thailand to engage with programs and play a greater role in supporting their implementation. However, concerns are expressed about the police acting as a hindrance rather than a support to drug users' willingness to access harm reduction services, and local communities can be skeptical and wary of police involvement. Certainly, the police locally require

\footnotetext{
${ }^{\dagger}$ In order to develop his understanding of community-based drug treatment in South East Asia, more generally, the researcher shared his perspectives at a workshop called Community-Based Treatment and Care Services Toolkit for People Affected by Drug Use and Dependence which helped to frame the ideas for the present paper. The workshop was held by UNODC between 23 and 24 April 2015 in Vientiane, Laos.
}

training about the evidence that demonstrates community-based drug treatment is a more effective approach than using criminal justice and compulsory detention systems, and the implications for their practice. But what are the views of stakeholders locally-community heads, health services, NGOs, as the local judiciary, and law enforcement officers themselves-about police involvement?

\section{Research Question}

The purpose of the present article is to examine the views of key stakeholders locally regarding the potential role of law enforcement officers in communitybased drug treatment in Thailand.

\section{Research Method}

The study utilized a qualitative methodology, which was in-depth, unstructured interview. The interviewees were given the opportunity to respond in a leisurely way (O'Reilly 2005). The structure of the interviews was sufficiently flexible to permit topics to be covered in the order most suited to each participant. General prompts were prepared in advance, derived from the policy literature, but were used only when a topic had not been mentioned by the participant. The research was able to pursue topics and issues as those arose through the spontaneous accounts of participants. According to Seal and Gobo (2004), an in-depth, unstructured interview format permits the researcher to explore fully factors underpinning participants' responses: reasons, feeling, opinions and beliefs.

Study data derived from eight key informants based in the Upper North of Thailand, who had been purposively selected due to their years of experience in responding to drug-related issues. Interviews were conducted with the senior members of the police and judiciary, hospital and community medical services, a representative of a civil society organization, and also the head of a group of villages (Kamnan). In addition to these individual interviews, six local village chiefs (Phuyaiban) were invited to a meeting to share ideas and provide information regarding community-based treatment approaches in their local areas. Afterwards, a senior member of staff from an NGO was interviewed later in Bangkok about the themes to emerge from the fieldwork.

The interviews in Chiang Mai were conducted during an intensive period of fieldwork, beginning with two senior judges, followed by the community head [and the group meeting of village heads], the staff 
Table 1: In-Depth Interview Schedule

\begin{tabular}{|c|c|c|c|}
\hline $\begin{array}{l}\text { Senior police manager } \\
\text { Local community police } \\
\text { Senior doctor } \\
\text { Group of villages head (Kamnan) } \\
\text { Civil society organization staff } \\
\text { Senior judges } \\
\text { Director Praw Hospital }\end{array}$ & $\begin{array}{c}\text { Provincial Police Region } 5 \\
\text { Provincial Police Region } 5 \\
\text { Northern Substance Abuse Center/Chiang Mai University } \\
\text { Ministry of Home Affairs } \\
\text { Civil society organization } \\
\text { Chiang Mai Court } \\
\text { Praw Hospital }\end{array}$ & $\begin{array}{l}\text { Upper North } \\
\text { Upper North } \\
\text { Chiang Mai } \\
\text { Upper North } \\
\text { Upper North } \\
\text { Chiang Mai } \\
\text { Chiang Mai }\end{array}$ & $\begin{array}{l}1 \\
1 \\
1 \\
1 \\
1 \\
2 \\
1\end{array}$ \\
\hline
\end{tabular}

member of a civil society organization, and then the two senior health professionals and managers. Finally, two police officers [one at administrative, the other at operational level] agreed to participate in interviews. The use of a tape recorder and taking short notes was consented by interviewees [excepting the two senior judges]. Immediately after, each interview was reviewed for emergent themes. Where necessary, new themes formed additional prompts for subsequent interviews. The series of interviews with key informants concluded when saturation of themes was reached. Then the interviews were transcribed and subjected to content analysis.

\section{FINDINGS AND DISCUSSION}

Key themes to emerge from content analysis of interview data are presented below. Extracts from those data have been translated into English from the original Thai.

\section{Community Networks and Empowerment}

In the study it was found local communities played an active role in promoting community-based drug treatment services, and providing critical supports. These included job opportunities for people in recovery and further education, along with a continuum of care for both treatment and prevention. Providing employment options, for example, were seen as important ways in which the community could support drug users. When they had viable opportunities for earning money they were less likely to commit crimes. One interviewee remarked:

A few drug users do not have jobs as they have been stigmatized by local members. We try to encourage them to apply for a job but it is not easy to get it. However, most of us decided to help them to earn money by raising animals and planting vegetables.

(The head of local community, Upper North)
Generally speaking, a model of community-based treatment services empowered local people to initiate treatment process. This process was decided based on clients' needs. Client participation in determining which treatment model to pursue was also linked to greater adherence and effectiveness, whether it included individual treatment, group therapy and family therapy. These modalities were best fit when they were able to draw on services of other agencies in a community network to support individualized client treatment arrangements. One local head stated:

When we were told by one family member about drug addiction of his son, we begin to scan other drug users in the village. When we find more drug users, we ask them first why you are involved with drug. Then, we will talk to drug users' guardians and ask them about solution... Often, we ask that do you want to send your child to the police or you want to treat them in local community.

(The head of local community, Upper North)

Resources need to be allocated to local communities for state health care making communitybased drug treatment accessible to everyone. Where a community does not have adequate resources, community-based drug treatment and care services need to be analyzed and interventions prioritized (UNODC, 2014). Basically, community-based treatment and care services have to rely on the capacity of local organizations and community members. National resources are insufficient when implemented at community level. A local senior doctor said:

It needs to be accepted that the state resources have never ever been sufficient for drug treatment program, particularly for remote areas. We have to solve the problem by ourselves. The community- 
based treatment program in this village can be maintained because we asked for funding from other sources. Budget from the Ministry of Public Health remains inadequate. Urine test strip, for instance, we had to request it from Northern Substance Abuse Center

(Senior doctor of local hospital, Upper North)

Establishing a multidisciplinary team seemed to be a key ingredient of community-based treatment because it provided better care to local members as clients through affordability, availability and informed services in a holistic framework (UNODC, 2008).

\section{Government Responses and the Treatment System}

Government responses to increasing criminal activity associated with illicit drug use have too often placed a taken-for-granted emphasis on its aggressive suppression and prohibition. While the relationship between drug use and its causal influence on crime and ancillary effects on the broader criminal justice system continue to be discussed, the pervasive culture, and concomitant mindset within many law enforcement agencies, remains geared toward aggressive enforcement. This entrenched culture continues to shape how law enforcement officers view their operating landscape. Across law enforcement agencies, great emphasis continues to be placed on traditional crime models and their suppression (Mayer and Erickson, 2015).

Law enforcement agencies often do not fully understand the role they can play in public health issues. People working at the local level and with affected communities are often best placed to assess the situation on the ground, and to help develop targeted and specific strategies to respond to the issues they face (Cook, 2010; Stoicescu, 2012). Nevertheless, in practice, local community still lacks cooperation between government agencies and civil society organizations and NGOs. It has had serious consequences for public health care and effective policing. A senior judge commented on the absurdity of the current situation:

...community drug treatment program is an interesting approach to cope with drug problems. This approach has been implemented for many years in Thai context. Yet, it is unlikely to be easily accomplished. One main obstacle is that each organization has its own styles and practices... Frequently, government policies are changed when a new government appears. This significantly leads to an ineffectiveness of drug treatment program. Sometimes, the government focuses on drug arrest and suppression. For example, a declaration of war on drug policy during former Prime Minister Thaksin period... On the other hand, a current government favors drug treatment strategies...

(Senior judge, Upper North)

Human rights and dignity are key concerns for community-based drug care and services. Drug treatment and rehabilitation are necessary to be delivered on the basis of human rights and human dignity (Human Rights Watch, 2004). Generally, drug users have been stigmatized and discriminated by the public in Thailand and many of them are afraid to come forward to health services. In some circumstances, a registration system has been provided by the state to collect drug users' identification. Furthermore, several clinics and medical staffs exchange this identification with law enforcement agencies when requested. This circumstance; however, invades confidentiality and violates human right to access to health care and services although there are also benefits to interagency information sharing. It is necessary to realize that enabling environment and supportive approach are vital. Medical care services should be low threshold, accessible and responsive to the needs of local people who use drugs (UNODC, 2014).

Enforcement of criminal prohibitions against drugs often prevents access to medical treatment. Drug users normally avoid medical services or harm reduction services because the police frequently patrol their vicinity. Drug user behavior increases their risky environment in respect of health care. Thus, various police organizations throughout the world, particularly in developed society, have reviewed their approaches toward high risk groups, and implemented effective policing to support drug treatment program which often includes a no-patrol zone near premises providing health services to drug users (LEAHN, 2012b).

In fact, drug users should be treated in the health care scheme rather than the criminal justice system. In addition, treatment scheme should be guided as an alternative way to imprisonment when possible. If it is 
impossible, prisons and confinement should provide drug dependence treatment, such as opioid substitution therapy. Once more, human right and human dignity principles should be strictly made in accordance with a continuity of medical service provision.

\section{Police Roles and the Treatment System}

The law enforcement sector has often acted as a barrier for harm reduction treatment programs. In Thailand, for instance, the provision of clean needles and syringes has been obstructed by the police because some senior officers believe that needles and syringe distribution encourages users to continue to use drugs. The provision of needles and syringes for the purpose of reducing transmission of blood-borne viruses, such as HIV, is still prohibited by drug laws. These laws must be revised and amended at policy level. Nonetheless, law enforcement officers in Thailand, as has happened around the globe, can use discretion and prioritize their activities towards improved health and community safety rather than arresting drug users. This would go some way to reducing some of the negative impacts of law enforcement practices on HIV risk by replacing arrest with a positive role for police in the delivery of good public health services.

In Thailand, arrest quotas have been set by policy makers pursuing a populist approach to drug law enforcement enabling the government to report that a high number of drug arrests were being made to the public. Politicians and political observers believe that this approach significantly increases favorable votes from the Thai community when a general election occurs. Arrest quotas place undue pressure on police to arrest drug users so as to reach the quota every week and every month or risk adverse impacts on their professional career. People most-at-risk of HIV are usually targeted in order for the police to meet their quotas. The requirement to meet arrest quotas also leads to overcrowded prisons which are known breeding grounds for serious diseases. Political pressure on police in Thailand was a major influence on police practices, as the one senior police officer mentions in the following quote:

We had to reach to the number of drug arrests every week. If we lack capability to do this, we will be removed from this position and transferred to another department. Quota was set by policy makers outside the force...
Police Law 2004 gives absolute authority to the Prime Minister in terms of the National Police Chief's removal and appointment. As a result, the Prime Minister's commands are likely to be more important than public requirements.

(Senior police officer, Upper North)

Whilst police have a major role to prevent crime and preserve public security, a high number of drug arrests are not an indication of effective policing activities. Furthermore, modern policing strategies for crime prevention and suppression should be sensitive to local needs (Poothakool, 2017). Police cannot successfully fight against crime on their own, strategies must be developed and delivered through intergovernmental and community-level partnerships (Bayley, 1994). It is clear that local communities and police need to be more engaged in responding to drug-related concerns in Thailand.

Improved collaboration between police and the local community can be beneficial for meeting police objectives in terms of preventing crimes and securing public safety (Crawford, 2007). Police have frequent contact with drug users which means they can play an important role in identifying drug users, conducting basic screening of drug problems and refer to primary health and harm reduction services if required. Providing policy makers allow police the space to use discretion when responding to drug-related issues, the police can give strong support to the patients' families and local community without resorting to strict drug law enforcement which has been shown to create serious harms. For example, instead of prosecuting drug users giving them criminal convictions, the police can act as a node in the treatment and harm reduction network which aims to secure job opportunities, skills and further education. Positive police engagement with health service providers and the community may also assist in deterring further drug users' involvement in illegal activities. It is obvious that police practices can influence social and health subjects that in turn determine effective responses to public health and community safety.

Police forces are often labeled as monolithic organizations with a bent towards strict drug law enforcement one senior police officer interviewed in for this study who has more than twenty years in the force supported the concept of police involvement in community-based drug treatment. He said: 
...it is a good idea to have the police at the beginning of drug treatment process within local community. The police can work closely with community leaders since they are familiar with local members. Additionally, information can be shared and used for both public health services and crime prevention.

(Senior police officer, Upper North)

Law enforcement officers traditionally have had a key role to play in communities concerning a wide range of public health issues, including mental health, road trauma, alcohol and other drugs, violence prevention, and many others (LEAHN, 2014). In reality, the role of law enforcement officers in local community can remove barriers to effective public health services and care. Furthermore, harm reduction services can engage a powerful ally in response to drug treatment when police are seen as potentially positive partners in the HIV response. Unfortunately, police-health partnerships can become strained, for example, in Thailand, the police often are forced to choose between political and community demands in responding to drug-related issues which may impact on drug users' willingness to access harm reduction services. Despite this, evidence throughout the world has shown that the decisive decision and critical contribution of the police appears not to be well recognized (LEAHN, 2012).

Whilst some police interviewees acknowledged that police support for community-based drug treatment was a good idea, inadequate officer numbers who are directly engaged in local community presents a major barrier. In practice, only a small number of the police maintain law and order and many officers rarely deal with crime prevention in their locality. In fact, the police have been assigned to do a wide range of jobs and their work is governed by over three hundred laws which make prioritization a political issue. At present, it lacks police officers working on the streets and in the communities. One local police officer stated that:

I have served as a local police officer for more than ten years. My main responsibilities are to prevent crimes and maintain public order at local level. However, over the past ten years, I have been called by my superior to work with riot police in Bangkok in order to control mob owing to political conflict and public turmoil. Therefore, it has not had sufficient police officers working in communities during that period.

(Local police officer, Upper North)

\section{Community Policing and Police Training}

Supportive communities are vitally necessary both for drug treatment and crime prevention. Community support can be delivered more effectively by community members in collaboration with local government agencies, civil society organizations and NGOs. The majority of drug users face significant social adaptation issues. These include family and community stigmatization and ostracism, and the ensuing negative impact on their ability to find jobs or housing, return to formal education or build or re-build individual and social capital (ONDC, 2015). If the communities understand and accept the importance of ensuring successful rehabilitation of drug users, they would remain willing to facilitate that process or to play an active role in rehabilitation. And this should be a main element of crime prevention strategy as well.

One key strategy of modern policing which successfully prevents crimes is community policing (Gilling, 2005). It is accepted that this is an effective strategy to deal with criminal acts in collaboration with local community. This strategy embraces the ideas of working closely with the public. Arrest and suppression are considered as a last resort (Lab, 2014). Police bureaucracy and the styles of police work are altered. Additionally, the whole policing system is restructured. On the contrary, the traditional policing model considers the arrest and detention of criminals as the main responsibilities of policing. Moreover, communityoriented policing systems address issues of power abuse by establishing working relationships between the police and the community members. Participatory management serves to supervise the police's actions in local communities and to reduce conflicts between officers and the public (McLaughlin, 2013).

Community-oriented policing generally is believed to produce more ethical officers by concentrating on internalized norms and values. The traditional model of policing, in contrast, embraces the notions of a bureaucratic system and sub-culture in which officers perform their tasks through the exercise their power and authority, whereas sustaining their distance from ordinary citizens. Community-oriented policing, however, has had the purpose of encouraging community residents to work more closely with police 
officers in resolving crime and addressing fear of crime in local neighborhoods. The key point being that the police cannot prevent crime on their own (Bayley, 1994: 59). Some commentators would go further in saying the police and the community must work together both to define and to develop solutions to problems (Sadd and Grinc, 1994).

When implementing the concepts of community policing into health care and services, the police and community can work together more effectively. Importantly people who are illicit drug users occasionally involved with illegal activities should also be considered valued participants in community engagement. Under the concepts of community policing, problem solving at community level appears to be more important than drug arrest. Civil society organizations, NGOs, drug users themselves and the police can work together to find out the best solution for a provision of medical care and drug treatment in parallel to crime prevention. More importantly, all of these aspects can be made by using local resources.

The member of the civil society organization supported this argument, and stated that:

When state budget was insufficient, drug treatment programs were ended. Then, government agencies at regional and local level just wait for a next round of the budget to run drug treatment activities. Unlike local community, it establishes the team and helps each other to treat young people who addicted drugs and substance abuse by using local resources. ...drug treatment methods provided by the state are unsuccessful and lack continuity.

(Staff member of a civil society organization, Upper North)

Community policing affirms that responses to community issues focus on local collaboration, resource sharing and joint ownership of the range of problems. The approach advocates a concerted effort be made to address the impact of illicit drug use by local police, and also an increase or broadening of their responses. Responses which can bridge the gap between the police and health services sectors so that the harms associated with illicit drug use are lessened (LEAHN, 2012).

The use of community policing approaches in drug treatment programs requires law enforcement officers with increased knowledge and skills. Local police who work collaboratively with local community needs to understand health issues related to crime prevention. More specifically, the police have to increase their capabilities to perform their tasks with other agencies in respect of a provision of health care services. Skills and knowledge are the core of effective service delivery. Properly trained police officers are able to carry out treatment procedures successfully. For example, trained law enforcement officers are to support the patients in gaining new skills for behavior change and self-control. They have to maintain proactively regular contact with the patients, particularly those who are drug users' families and friends to ensure that multiple drug use and illegal acts have not been executed. It is necessary to systematically reinforce attempts towards law enforcement officers' positive changes that support the goals and mission of community based treatment and crime deterrence.

Improved training systems could aid the police to have more understanding about drug dependence in which it is considered as a complex health problem combining social, mental and physical aspects. In the context of law enforcement, illicit drug use is regarded as criminal behavior (UNODC, 2014). If the police recognize the value of a health approach to drug use and dependence, a positive paradigm of communitybased care can occur. Instead of arresting drug users, for example, people suspected of using drugs can be referred to NGO staff, peer educators and outreach workers whenever possible. When drug users arrive in health care centers, a designated community case manager will employ screening and assessment process.

Police can play a leading role to develop treatment programs that intend to reduce drug problems in relation to individuals and communities. The police can implement a wide range of strategies to cope with people who affected by drug use and dependence (LEAHN, 2015). Such strategies are useful for the police for saving their budgets and time to deal with minor offences. On the other hand, the police can spend more time to tackle more serious crimes such as drug market, robberies and assaults. Clearly, alternative approaches are more effective than punishment or compulsory centers for those who are drug users.

Human rights obligations are another key concern which should be addressed in police training programs. These include human dignity, stigmatization and 
discrimination. According to the research, it is acknowledged that police perceptions towards such drug users and most at risk populations tend to be adjusted after being trained. However, police training system at operational level is necessary to be continued and developed.

Continuous improvement to enhance co-operation in bringing about successful integration is fundamental for community-based drug treatment. An interaction between key stakeholders must be continuous and progressive with agreed objectives and a willingness on all sides to respect others viewpoints and limitations. Law enforcement agencies and the public health sector, in particular, can perform their tasks together to achieve their main objectives although cooperation and partnership cannot be taken for granted. The process must be respected and nurtured and representatives of all key stakeholders need to be selected carefully so that true collaboration and problem solving can occur. Medical staffs can provide health care and services, whereas the police can support all of these aspects. Furthermore, the police can access to drug users and most at risk populations at early stage in connection with medical team before they are engaged in illegal acts. Close collaboration would preserve treatment program development, improve quality of lives of these people in needs and prevent criminal phenomena. Research evidence shows that the presence of harm reduction services does not increase localised crime or increase drug use (LEAHN, 2015).

Whilst police officers have well recognized responsibilities to maintain public safety and security, these responsibilities inevitably involve the community. Community engagement has been shown to assist the police to accomplish their work more efficiently, whilst improving legitimacy and accountability (Changwon and Monica, 2011). In Thailand, the police consider prevention of drug use a priority and local police frequently address educational institutions to educate young people about drugs and crimes. When the community understands and realizes the risks of drug use and the benefits of seeking treatment early, community awareness and support will be increased and drug-related crime problems in local communities are likely to be diminished.

One key informant cautioned that the role that law enforcement officers are able to play in practice in community-based drug treatment programs would need to be evaluated. However, this would require to develop a more community-oriented, responsive and open law enforcement culture. This is a key aspect of programs needed to assess how well the local community, its alliances and the law enforcement are able work together. Evaluation outcomes would need to be shared and utilized between community members, local organizations and law enforcement officers for development of collaborations. Some ineffective and inappropriate activities can be changed and improved so as to meet clients' needs in accordance with crime reduction. All organizations both private and public sectors to need to evaluate themselves. The interviewee stated that:

Evaluation results are very important
because it helps us to improve medical
services and methods that we use. Drug
rehabilitation program can be adjusted on
the basis of those results... All local
partners within the network or
organizations should use the evaluation
outcomes for formulating a new drug
treatment program.

(Senior doctor, Upper North)

\section{CONCLUSION}

It is clear that the police are considered the key players for public order and safety in Thailand. They have to deal with criminal phenomena and protect citizen's right in their daily work. However, that the police also have a public health role in assisting drugrelated harm reduction in local neighborhoods has to be accepted and acted upon.

Closer collaboration between local organizations and the police is crucial for the success of communitybased drug treatment, as part of a multidisciplinary team comprised of community members, government agencies, civil society organizations, NGOs, police and other key stakeholders, who can create and choose appropriate methods by acknowledging the complex needs of each individual case.

In principle law enforcement officers can work collaboratively within a multidisciplinary team to identify drug users, offer basic screening and help families and communities to address drug use and other related issues. Yet, in practice in Thailand, local communities still lack effective cooperation with the police in responses to illicit drug use.

In modern law enforcement, community policing offers at least one strategy to respond to such issues 
through its focus on collaboration, resource sharing and joint ownership of the range of problems. There has been a concerted effort by law enforcement to address the wider community impact of illicit drug use, and a broadening of responses. In Thailand, the challenge is to engage with those responses to bridge the gap between the police and health services sectors so that harms associated with illicit drug use are lessened.

Training is a major component aiding law enforcement officers to develop understanding about drug dependence, and effective responses to illicit drug use as more than criminal behavior. If the police have been educated about the value of a public health approach to drug use and dependence, a positive paradigm of community-based care becomes more likely. People suspected of using drugs can be referred to NGO staff, peer educators and outreach workers whenever possible. This requires training police officers to recognize human rights obligations, the need for self-evaluation as part of their collaboration with local communities and services.

\section{REFERENCES}

Bayley, D. H. (1994) Policing for the future. New York: Oxford University Press.

Bayley, D. H. (2002) 'Law Enforcement and the Rule of Law: Is there a Trade off?' Criminology and Public Policy, 2 (1), 133-154. https://doi.org/10.1111/j.1745-9133.2002.tb00113.x

Changwon, P. and Monica, D. B. (2011) Good Policing: Instruments, Models and Practices. Singapore: Asia-Europe Foundation.

Crawford, A. (2007) Crime prevention and community safety. In $M$. Maguire, R. Morgan and R. Reiner (Eds), The Oxford Handbook of Criminology (4th ed.) Oxford, UK: Oxford University Press.

Cook, C. (2010) The Global State of Harm Reduction: Key issues for broadening the response The Global state of harm reduction. London: Harm Reduction International.

Crofts, N., Tim M., Brigitte T. and Nick T. (2012) Law Enforcement and Harm Reduction in SE Asia: examining policing and harm reduction in Cambodia, Laos and Vietnam. Retrieved December 3, 2017 (http://www.harmreductionjournal.com/ series/policing).

Graham, J. (1995) Crime prevention strategies in Europe and North America. Helsinki Institution for Crime Prevention and Control. New York: Criminal Justice Press.

Gilling, D. (2005) Partnerships and crime prevention. In N. Tilley (Ed), Handbook of crime prevention and community safety. Portland, OR: Willan Publishing.

Gordon, D. R. (2001). 'Democratic Consolidation and Community Policing: Conflicting Imperatives in South Africa'. Policing and Society,11(2), 121-150. https://doi.org/10.1080/10439463.2001.9964859

Harm Reduction International (2015) What is harm reduction? Retrieved May 21, 2015 (http://www.ihra.net/what-is-harmreduction).

Human Rights Watch (2004) Not Enough Graves: The War on Drugs, HIVIAIDS, and Violations of Human Rights. New York: Human Rights Watch.
Jacobs, B. et al (2012) Addressing access barriers to health services: an analytical framework for selecting appropriate interventions in low-income Asian countries, Health Policy and Planning, 27, 288-300.

https://doi.org/10.1093/heapol/czr038

Law Enforcement Agencies and HIV Network [LEAHN] (2014) Policing and public health. Retrieved January 25, 2014 (http://www.leahn.org)

Law Enforcement Agencies and HIV Network [LEAHN] (2012a) Report on International Consultation on Policing of Most-atRisk Populations, Rome.

Law Enforcement Agencies and HIV Network [LEAHN] (2012b) The International Police Advisory Group (IPAG) of the Law Enforcement Agencies and HIV Network, Statement of Support by Law Enforcement Agents for Harm Reduction and Related Policies for HIV Prevention, Melbourne.

Law Enforcement Agencies and HIV Network [LEAHN] (2012) The International Police Advisory Group (IPAG) of the Law Enforcement Agencies and HIV Network, Statement of Support by Law Enforcement Agents for Harm Reduction and Related Policies for HIV Prevention. Melbourne: Australia.

Law Enforcement Agencies and HIV Network [LEAHN] (2015) Policing and public health. Retrieved May 5, 2015 (http://www.leahn.org).

Lab, S. P. (2014) Approaches, practices and evaluations in crime prevention. New York: Routledge.

Maguire, M., Morgan, R. and Reiner, R. (2012) The Oxford Handbook of Criminology, Fifth Edition. Oxford: Oxford University Press. https://doi.org/10.1093/he/9780199590278.001.0001

Mayer, M. A. and Erickson, S. G. (2015) Changing Today's Law Enforcement Culture to Face 21st-Century Threats. Retrieved May 9, 2015 (http://www.heritage.org/research/ reports/2011/06/changing-todays-law-enforcement-cultureto-face-21st-century-threats).

McLaughlin, E. (2013) The new policing. London: Sage Publications.

Monaghan, G. (2012) Harm Reduction and the Role of Police Services, in R. Pates and D. Riley (eds) Harm Reduction in Substance Use and High-Risk Behaviour. Oxford, WileyBlackwell.

Office of National Drug Control Policy [ONCB] (2015) Break the Cycle of Drug Use, Crime, Delinquency, and Incarceration. Retrieved January 20, 2015 (https://www.whitehouse.gov/ ondcp/break-the-cycle-of-drug-use-crime-delinquency-andincarceration/).

Office of the Narcotics Control Board [ONCB] (2018) Communitybased drug treatment. Retrieved January 20, 2015 (https://nctc.oncb.go.th/main.php?filename=index).

O'Reilly, K. (2005) Ethnographic methods. London: Routledge and Kegan Paul. https://doi.org/10.4324/9780203320068

Seal, C. and Gobo, G. (2004) Qualitative research practice, London: Sage. https://doi.org/10.4135/9781848608191

Poothakool, K. (2012) Literature review on policing system over the past five years: 2007-2012. Ministry of Justice.

Poothakool, K. and Glendinning, A. (2013) 'Police Reform in Thailand Post-2006.' International Journal of Criminology and Sociology, Vol.2, 371-384.

Poothakool, K. (2017) Crime prevention over the next decade and policing system reform. Nonthaburi: Matichon Printing.

Sadd, S. and Grinc, R. (1994) 'Innovative Neighbourhood Oriented Policing: An Evaluation of Community Policing in Eight Cities'. In: Dennis P. R. (ed.), The Challenge of Community Policing. CA: Sage Publications.

Sapsford, R. and Jupp, V. (1996) Data collection and analysis. London: Sage Publication Ltd. 
Stoicescu, C. (2012) The Global State of Harm Reduction 2012:Towards an integrated response The Global state of harm reduction. London: Harm Reduction International.

UNAIDS (2010) Reducing Harm, Rebuilding Lives: HIVIAIDS and High Risk Populations. Law Enforcement Agencies as Agents of Change. Geneva: UNAIDS.

UNAIDS (2013) Global Report: UNAIDS Report on the Global AIDS Epidemic. Geneva: Switzerland.

United Nations Office on Drugs and Crime [UNODC] (2008) Community Based Treatment: Good Practice.

Retrieved March 20, 2015 (http://www.unodc.org/docs/treatment/ CBTS_AB_24_01_09_accepted.pdf).
United Nations Office on Drugs and Crime [UNODC] (2012) HIV prevention, treatment and care in prisons and other closed settings: a comprehensive package of interventions. Vienna: UNODC.

United Nations Office on Drugs and Crime [UNODC] (2013) National Consultant: Law Enforcement Liaison Advisor on HIV. Bangkok: UNODC.

United Nations Office on Drugs and Crime [UNDOC] (2014) Community Based Treatment and Care for Drug Use and Dependence: Information Brief for Southeast Asia. Bangkok: UNODC.

DOI: https://doi.org/10.6000/1929-4409.2018.07.18

(C) 2018 Krisanaphong Poothakool; Licensee Lifescience Global.

This is an open access article licensed under the terms of the Creative Commons Attribution Non-Commercial License (http://creativecommons.org/licenses/by-nc/3.0/) which permits unrestricted, non-commercial use, distribution and reproduction in any medium, provided the work is properly cited. 